\title{
The Role of MAPK in Drug-Induced Kidney Injury
}

\author{
Hilary Cassidy, Robert Radford, Jennifer Slyne, Sein O’Connell, \\ Craig Slattery, Michael P. Ryan, and Tara McMorrow
}

Renal Disease Research Group, School of Biomolecular and Biomedical Sciences, UCD Conway Institute, University College Dublin, Belfield, Dublin 4, Ireland

Correspondence should be addressed to Tara McMorrow, tara.mcmorrow@ucd.ie

Received 15 August 2011; Revised 2 November 2011; Accepted 4 November 2011

Academic Editor: Peter van der Geer

Copyright () 2012 Hilary Cassidy et al. This is an open access article distributed under the Creative Commons Attribution License, which permits unrestricted use, distribution, and reproduction in any medium, provided the original work is properly cited.

This paper focuses on the role that mitogen-activated protein kinases (MAPKs) play in drug-induced kidney injury. The MAPKs, of which there are four major classes (ERK, p38, JNK, and ERK5/BMK), are signalling cascades which have been found to be broadly conserved across a wide variety of organisms. MAPKs allow effective transmission of information from the cell surface to the cytosolic or nuclear compartments. Cross talk between the MAPKs themselves and with other signalling pathways allows the cell to modulate responses to a wide variety of external stimuli. The MAPKs have been shown to play key roles in both mediating and ameliorating cellular responses to stress including xenobiotic-induced toxicity. Therefore, this paper will discuss the specific role of the MAPKs in the kidney in response to injury by a variety of xenobiotics and the potential for therapeutic intervention at the level of MAPK signalling across different types of kidney disease.

\section{Introduction}

Intracellular signalling cascades are the primary routes of communication between the plasma membrane and regulatory targets in various intracellular compartments. Sequential activation of kinases is a widely conserved mechanism of signal transduction in many cellular processes. Protein kinases are ubiquitous enzymes that modulate the activities of other proteins through the addition of phosphate groups to tyrosine, serine, or threonine amino acid residues, a process referred to as phosphorylation. Over the last decade, several related intracellular signalling cascades, collectively known as mitogen-activated protein kinase (MAPK) signalling cascades, have been characterized. MAPKs belong to a large group of serine/threonine protein kinases which have been shown to be conserved in organisms as diverse as yeast and humans [1-3], and which can be activated by numerous extracellular stimuli $[4,5]$. In combination with several other signalling pathways, MAPKs can differentially alter the phosphorylation status of numerous proteins including transcription factors, cytoskeletal proteins, kinases, and other enzymes and can significantly influence gene expression, metabolism, cell division, cell morphology, and cell survival.
Epigenetic aberrations of these enzymes, or of the signalling cascades that regulate them, have been implicated in a variety of human diseases including cancer, inflammation, and cardiovascular disease. Dysregulation of normal MAPK signalling has also been implicated in both acute and chronic kidney disease. In this paper we focus on the role of MAPKs in kidney disease, and in particular, the role that MAPK signalling plays in drug-induced kidney injury and disease.

\section{The MAPK Family in Kidney Injury}

The transmission of extracellular signals to various intracellular targets is a multifaceted process which often involves the activity of one or more MAPKs. The process begins in response to external stimuli such as binding of a growth factor to its associated receptor on the cell surface. The resulting activation of the integral or associated protein tyrosine kinases contained within the intracellular domain of the receptor then initiates intracellular signalling events. Activation of a MAPK employs a core three-kinase cascade whereby a MAPK kinase kinase (MAP3K or MAPKKK) phosphorylates and activates a MAPK kinase (MAP2K or MKK) which in turn phosphorylates one or more MAPKs 


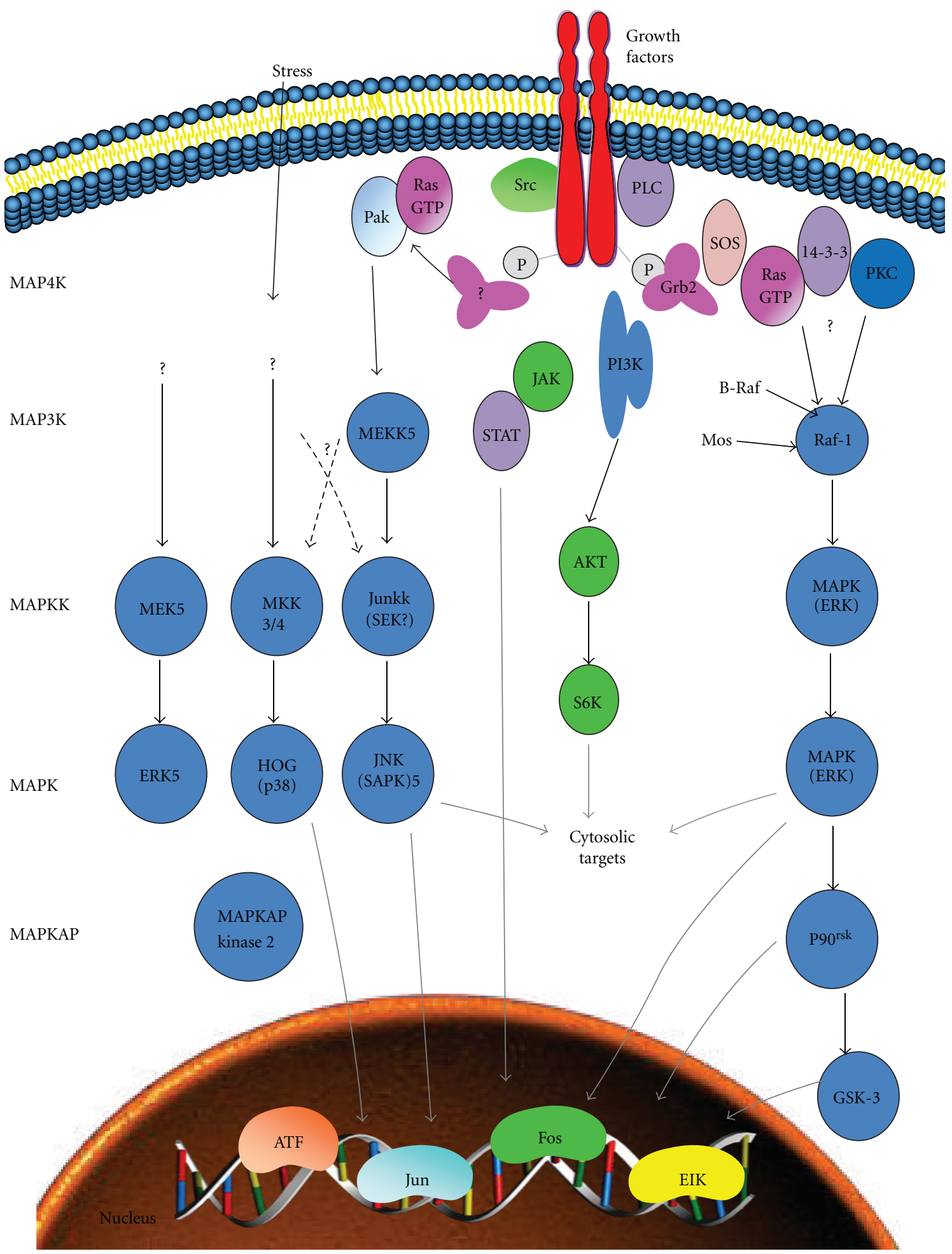

Figure 1: The MAP kinase signalling pathways (adapted from http://www.sabiosciences.com/).

[6-8]. An overview of the signalling pathways is outlined in Figure 1. Once activated, MAPKs can phosphorylate several different intracellular targets including transcription factors, nuclear pore proteins, membrane transporters, cytoskeletal elements, and other protein kinases [8-10]. This threetier module mediates ultrasensitive switch-like responses to stimuli. Uniquely, MAPKs themselves can be activated by addition of phosphate groups to both their tyrosine and threonine amino acids (dual phosphorylation) after stimulation of a receptor by growth factors, mitogens, hormones, cytokines, or environmental stresses [11]. These various members of the MAPK family have been duplicated 
with slight variations, allowing cells to instigate multiple biological responses through a set of MAP kinase networks.

2.1. ERK 1/2 Signalling Cascade. In the early 1980s, the $42 \mathrm{kDa}$ extracellular signal-regulated protein kinases 1 and $2($ ERK1/2) were the first members of the MAPK family to be identified and cloned from a vertebrate species [1216]. ERK1/2 functions have been linked to the regulation of growth and differentiation $[17,18]$. ERK1/2 activation is mediated by the specific protein kinases MAPK/ERK kinases (MEK) $1 / 2$, which are members of the MAPK supergene family MEK2. MEK1 and MEK2 are encoded by different genes, but are very similar in terms of sequence, substrate specificity, and regulation $[19,20]$. MEK1/2 themselves are activated through phosphorylation by three distinct MAPKK kinases (MAP3K or MAPKKK), Raf, c-Mos, and MEK kinase (MEKK). The major pathway by which tyrosine kinase mediated signals are directly conveyed to the ERK1/2 cascade is through Ras-mediated recruitment of Raf to the plasma membrane. Ras activation is dependent on the tyrosinekinase-mediated membrane translocation of the guanine nucleotide exchange factor SOS by the Grb2 adapter protein, which connects SOS to the tyrosine-phosphorylated receptor [21]. Elk-1 and SRF are target genes regulated by ERK1/2 [6]. An overview of the ERK1/2 signalling pathway is outlined in Figure 2.

ERK signalling plays a major role in mediating renal cell responses to a diverse range of stimuli and has previously been shown to be involved in compensatory renal hypertrophy and pathological conditions such as glomerular and tubulointerstitial diseases. Robust ERK activation has been detected in the cyst epithelium in polycystic kidney disease (PKD), while inhibition of the ERK pathway led to inhibition of cyst-induced gain in kidney mass and improved renal function [22]. In instances of drug-induced nephropathy such as kidney injury associated with cisplatin administration, stimulation of ERK occurs via the EGF-R/Src cascade [23]. Cisplatin-induced nephrotoxicity is dependent on DNA damage-induced apoptosis. Conversely, inhibiting ERK in vivo, in a rat model of progressive membranous nephropathy (PHN), was demonstrated to worsen DNA damage observed in the podocytes and resulted in an upregulation of p21, suggesting a protective role of ERK in this model [24]. This suggests a dual nature of this particular MAPK: on the one hand mediating a kidney injury response while on the other hand playing a role in renal defence.

2.2. JNK Signalling Cascade. The JNK cascade was first discovered through studies on the oncogenic cooperation between Ras and the target JNK transcription factor c-Jun, and on the activation of transcription factor AP-1 by UV irradiation [25]. Both studies indicated that phosphorylation of a component of AP-1 at Ser63 and Ser64 occurred in response to either Ras activation or UV irradiation such phosphorylation, especially at Ser73, enhances the ability of c-Jun to activate gene transcription [26]. The protein kinases that bind to c-Jun and phosphorylate it at Ser63 and Ser73 were subsequently identified as JNKs. There are two JNK polypeptides, the products of two distinct genes, and they share $81 \%$ sequence identity [27]. Like all MAPKs, the JNKs are activated by phosphorylation on conserved threonine and tyrosine residues. Consistent with the different sequences surrounding their activating phosphorylation sites, the JNKs are not phosphorylated by MEK1/2 but by another MAPKK, named SEK 1, MKK4 or JNKK1. Similar to other MAPKKs, JNKK1 is phosphorylated and activated by a MAP3K called MEKK1 [28]. An overview of the JNK signalling pathway is outlined in Figure 3. Activation of JNKK1 by MEKK1 was demonstrated in vitro [29]. Very strong JNK activation is observed after irradiation of cells with either UV light or treatment with certain translational inhibitors such as anisomycin, exposure to IL-1, costimulatory activation of T-cells, ischemia reperfusion, and exposure to alkylating agents. JNK activation is also observed after treatment of certain cell types with growth factors such as EGF and NGF. The mechanisms by which these stimuli activate the JNK cascade have not been elucidated. The majority of experimental analysis has focused on the mechanisms of JNK activation by growth factors and members of the Src family of tyrosine kinases $[28,30]$.

In the context of renal injury, JNK signalling is mediated by different insults including ischaemia/reperfusion (I/R), ureteric ligation, immune-mediated injury, and hyperglycaemia [31, 32]. JNK activation has been demonstrated in several glomerulonephritides [33], and JNK inhibition suppresses inflammation in rat antiglomerular basement membrane disease [34] and also suppresses tubular apoptosis and interstitial fibrosis in unilateral ureteral obstruction (UUO) models [35]. Kanellis et al. demonstrated that acute activation of JNK signalling occurs following I/R, with higher JNK activation detected in deceased donor compared to live donor allografts, thus suggesting that increased JNK reflects greater ischaemic damage [36]. Administration of a JNK inhibitor prior to $\mathrm{I} / \mathrm{R}$ injury prevented tubular damage and renal dysfunction, suggesting involvement of JNK activation in both cellular rejection and acute tubular necrosis [36].

2.3. P38 Signalling Cascade. p38 is another MAPK protein, which is most similar to the yeast MAPK HOG-1 which is activated in response to osmotic shock [37]. Like HOG-1, p38 is also activated in response to osmotic shock, as well as by LPS and IL-1. For the most part, p38 also responds to the same agonists that activate the JNKs. The similarity between the regulation of p38 and JNK is not surprising since JNKK1 (SEK1) is also a direct activator of p38. Downstream targets of $\mathrm{p} 38$ include the genes MAPKAP kinases 1 and 2 and ATF-2 $[38,39]$. p38 MAPK is an important regulator of senescence growth arrest due to its ability to activate both the p53 and $\mathrm{pRb} / \mathrm{p} 16$ growth arrest pathways. 338 MAPK inhibition has been demonstrated to moderately delay replicative senescence [40]. Furthermore, p38 MAPK activity is required for the senescence arrest caused by oncogenic RAS, and constitutive p38 MAPK activity can induce a growth arrest in normal human cells [41, 42]. p38 MAPK is known to upregulate specific cytokines such as IL-6, IL-8, and TNF $\alpha$ in several biological contexts including kidney damage 


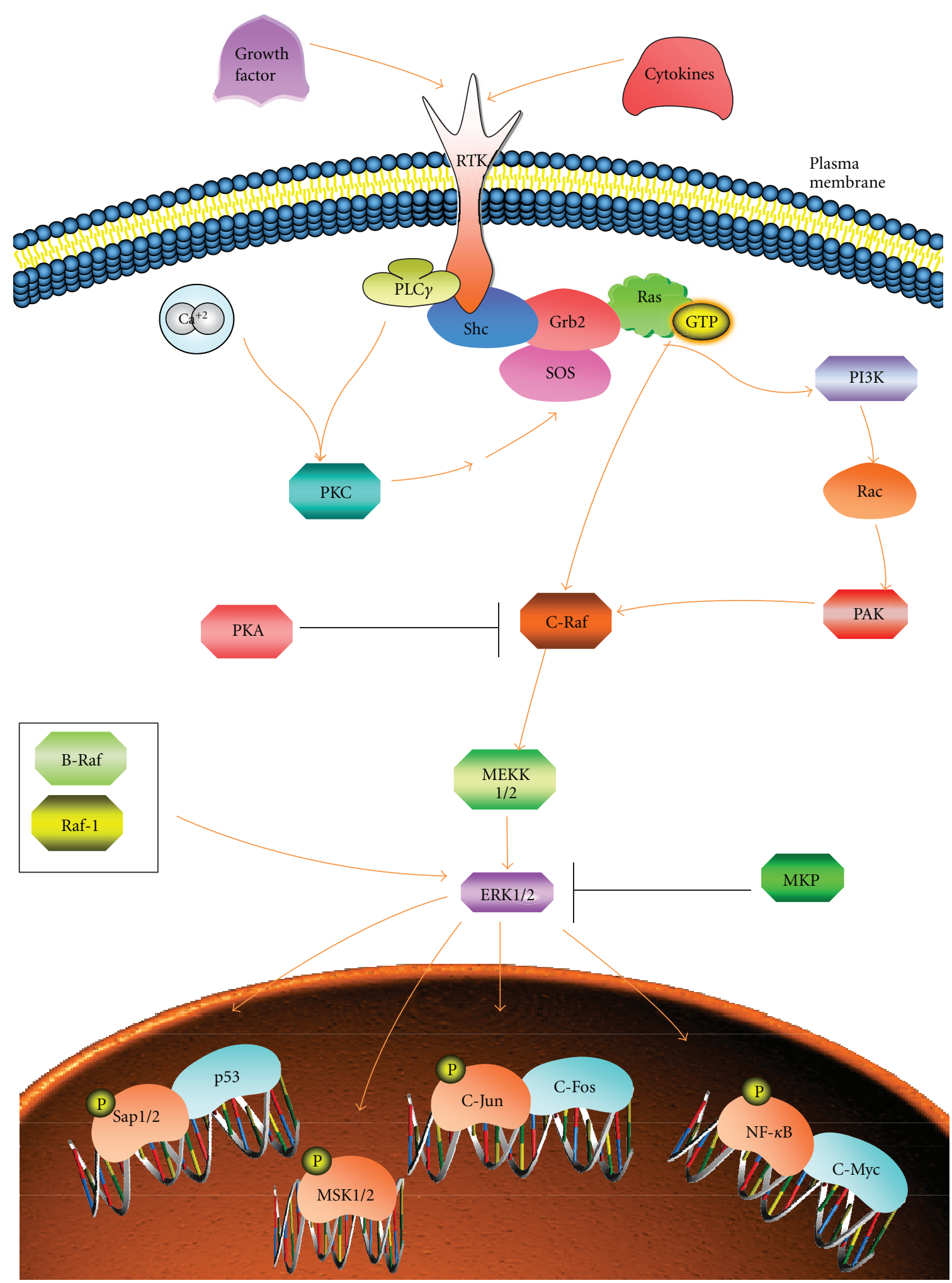

FIGURE 2: Structure of the ERK pathway (adapted from http://www.sabiosciences.com/). Upon ligand binding, RTK autophosphorylates on tyrosine residues, which serve as docking sites for adaptor and signalling molecules. Ras is activated by the recruitment of guanosinenucleotide exchange factors (SOS, C3G) via adaptor proteins (Shc and Grb2; Crk). Ras can activate Raf-1 and B-Raf; Rap1 presumably can activate B-Raf. Raf proteins phosphorylate and activate MEK-1/2, which in turn activate ERK-1/2 (indicated by black arrows). 


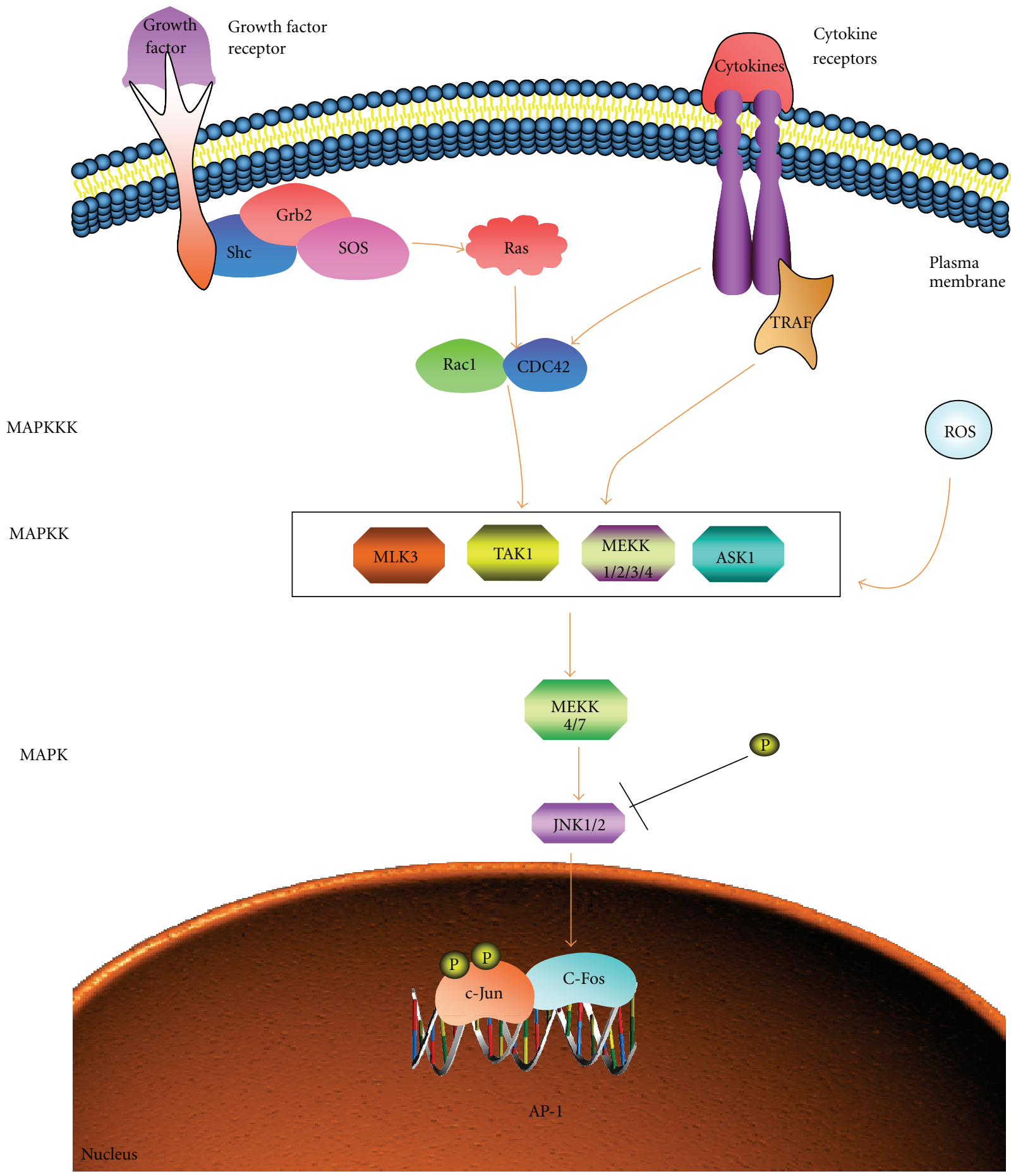

FIGURE 3: The JNK signalling pathway (adapted from http://www.sabiosciences.com/). Upstream events are poorly defined, but in the case of growth factors and the cytokine TNF are known to involve G proteins such as Rac and cdc-42 and the protein TRAF2. Activated JNK1 and JNK2 isoforms phosphorylate the AP-1 subunit c-Jun, increasing its transcriptional activity. ASK1, apoptosis signal-stimulating kinase 1 ; MLK, mixed-lineage protein kinases; TAK1, transforming growth factor- $\beta$-activated kinase- 1 .

$[39,43,44]$. An overview of the p38 MAPK signalling pathway is outlined in Figure 4. p38 MAPK activity has been shown to be necessary and sufficient for the development of a senescence-associated secretory phenotype (SASP). SASP is a persistent, nonacute inflammatory response in cells which have been induced to senescence by direct DNA damage or oncogenic RAS [45-47].

It has been reported that inhibition of p38 MAPK in autoimmune renal disease reduced the severity of the disease, resulting in a prolonged life span in MRL-Fas ${ }^{l p r}$ mice [48]. 

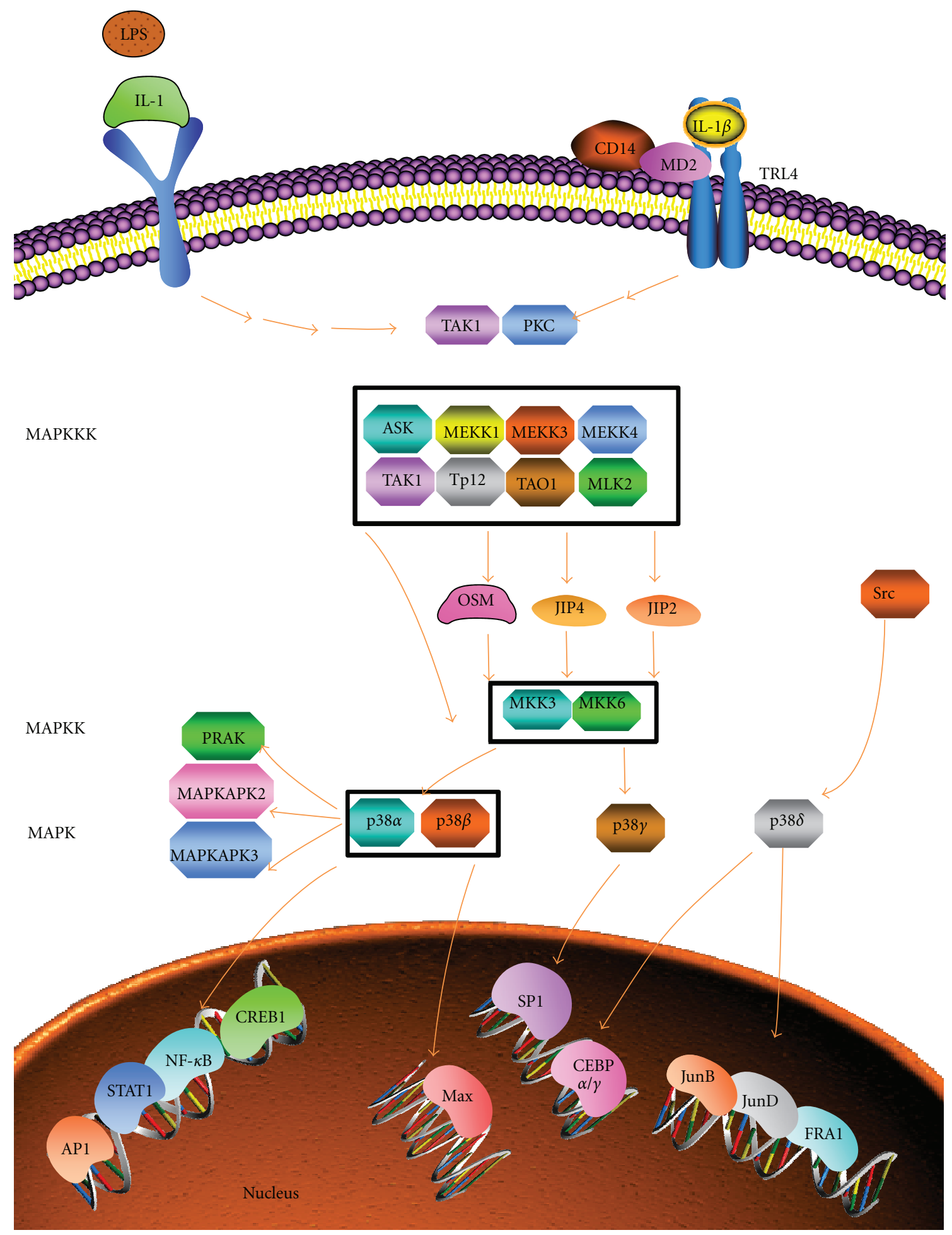

FIGURE 4: The p38 signalling cascade (adapted from http://www.sabiosciences.com/). RNA-binding proteins mediate regulation of cytokine mRNA stability through p38/MK2 signalling. LPS activates p38 MAPK signalling in a variety of cells, leading to transcriptional activation of cytokine genes or enhanced mRNA stability and translation (highlighted areas). The fate of adenine- and uridine- (AU-) rich elements (ARE) mRNA is dependent on the presence of destabilizing and stabilizing mRNA-binding proteins. p38 MAPK activates MK2 in the nucleus, allowing for MK2 translocation to the cytoplasm. MK2 subsequently phosphorylates destabilizing mRNA-binding proteins such as TTP. This action prevents TTP from interacting with ARE cytokines. Simultaneously, activation of the p38 MAPK pathway results in translocation of $\mathrm{HuR}$, a stabilizing RNA-binding protein, from the nucleus to the cytoplasm. Thus, upon p38/MK2 activation and phosphorylation of TTP, cytokine mRNA stability is enhanced, because TTP is no longer dictating mRNA triage and exonuclease decay. 
This protection against renal injury in vivo resulted from reduced infiltration of leukocytes, diminished expression of cytokines which are known to promote renal injury, and reduced production of Ig, leading to the conclusion that activation of p38 MAPK is required to promote cytokine/chemokine and Ig production, which in turn result in lethal autoimmune renal injury in vivo. Stambe et al. localized components of the p38 MAPK pathway to podocytelike cells, endothelial cells, and infiltrating neutrophils in a model of acute renal inflammation [49]. A similar pattern of p38 activation was observed in postinfectious glomerulonephritis [49]. It was shown that blockade of the p38 pathway significantly inhibited acute renal failure and proteinuria in rat anti-GBM glomerulonephritis via a neutrophil-platelet and P-selectin-dependent mechanism, thus suggesting that blockade of the $\mathrm{p} 38$ MAPK pathway may be a novel therapeutic strategy for the treatment of acute renal inflammation.

2.4. Ras Signalling. Ras is a small GTP-binding protein with multiple effector molecules, each of which defines a pathway with specific functions. Ras has been implicated, to different extents, as a mediator of ERK, JNK, and p38 activities. p38 has been implicated in cell motility stimulated by PDGF, in a Ras-dependent pathway [50]. Phosphatidylinositol 3-kinases (PI3K) have been suggested to be involved in cell motility through Ras-mediated activation of Rac. Rac is a member of the Ras superfamily of small GTP proteins which has a wellestablished role in cell migration and invasiveness [51-53]. Rac can be activated by Ras directly via recruitment to the cell membrane or via Ras activation of PI3Kinase. In contrast to its functions in motility, Rac has been shown unambiguously to strengthen cell-cell adhesion thereby preventing tumour cell invasiveness $[54,55]$. Studies have shown these opposing effects of Rac arise due to dependency on the cell substrate [56]. On substrates permissive for locomotion, expression of active Rac promotes motile behaviour, whereas, on substrates impeding cell motility, Rac-dependent cell-cell adhesion is favoured.

Other members of the Ras superfamily of small G proteins are Rho and Cdc42. Along with Rac, Rho and Cdc42 control different aspects of the cytoskeleton and seem to act in a cascade in which Cdc42 acts upstream of Rac which in turn acts upstream of Rho. Rho displays complex functions in cell scattering and it is involved in the assembly of focal contacts and actin stress fibres in fibroblast cells [57, 58]. Rho plays a positive role in colony-stimulating factor-1 induced macrophage translocation and in the migration and metastatic properties of human hepatocellular carcinomas [59]. Rho carries out these actions by stimulating the phosphorylation of myosin light chain and adducin, an actin-binding protein [60]. Like Rac, Rho can also have antagonistic effects on epithelial cell scattering by reinforcing cell-cell adhesion sites. Again, like Rac, the contrasting Rho activity is cell substrate dependent [61].

Activated Ras is sufficient for full ERK activation but is only a weak JNK activator producing about one-third of the JNK activity observed after treatment with EGF or expression of v-Src. Rac and cdc42 are effective JNK activators and can act synergistically with Ras. It is proposed that Rac in turn can stimulate Pak1 via cdc42, which could induce phosphorylation of myosin light chain, thus linking this Ras/Rac-induced pathway to proteins directly affecting cell movement $[37,62]$. Pak1 has been demonstrated to induce modest activation of JNK suggesting autocrine upregulation of JNK signalling.

2.5. Src Signalling. Src tyrosine kinase is another positive regulator of growth-factor-induced cell scattering [63]. Src belongs to a family of cytoplasmic tyrosine kinases. These enzymes have a pivotal role in the regulation of a variety of biological functions which are associated with changes in morphology, including malignant transformation $[64,65]$, epithelial plasticity [66], and modulation of intercellular adhesion [67]. In addition, the Src family is required during mitogenesis induced by EGF, PDGF, and colony-stimulating factor-1 $[68,69]$. Src regulates much of the activities of the JNK and p38 pathways. There are nine members in the Src family; Src, Fyn, and Yes are ubiquitously expressed while the other members have a more restricted pattern of expression. There is a possibility of redundancy of function amongst the Src family members [70] so the specificity of action of each individual member is not clear. This redundancy can arise by the phosphorylation of common substrates important for signalling, and it is probable that Src and Yes have redundant functions during cell scattering [71]. Three mechanisms by which Src kinases exert their functions have been suggested. Firstly, Src may phosphorylate specific substrates that are mainly cytoskeletal-based components, and molecules localised in cell-cell and cell-substrate adhesion sites, tyrosine phosphorylation of which could in turn alter cellular architecture [72-75]. Secondly, by inducing Myc via a specific transduction pathway, Src may also participate in entry into S-phase [76]. Finally, Src could interact with other signalling pathways, as it has been shown that it is capable of binding Shc, an early element of the Ras cascade leading to the activation of this pathway $[77,78]$.

A role for Src signalling in the repair mechanisms of acute kidney injury has also been indicated. A recent study by Takikita-Suzuki et al. has provided evidence to suggest the importance of active Src kinase in the early phase of PDGF-B-dependent nephrogenic repair after acute ischemia/reperfusion injury and has identified the distribution of active Src kinase in the normal and reperfused kidney [79].

\section{Drug-Induced Kidney Injury}

The anatomical, biochemical, and physiological specialisations which permit the kidney to perform its vital roles in homeostasis may increase the risk of drug exposure to the components of the nephron, and its ancillary structures. The kidneys receive $25 \%$ of cardiac output, filtering $180 \mathrm{~L}$ of plasma, producing $1.5 \mathrm{~L}$ of urine each day. As a result, high levels of drugs may be concentrated, leaving the epithelium of the nephron at a significantly greater risk of damage 
from pharmaceutical agents. In addition, the kidney is a metabolically active organ which contributes significantly to metabolism of xenobiotics. While renal metabolism usually contributes to the detoxification of xenobiotics, there are instances whereby substances undergo bioactivation to more toxic metabolites [80]. In addition to glomerular filtration, removal of xenobiotics and waste products from the blood can occur via transcellular transport, which transports compounds directly from the blood into the lumen by organic ion transporters. This organic ion transport system may allow toxic compounds to accumulate in the cells of the nephron which may otherwise not gain access to the cytosol [81].

\section{Antibiotic-Induced Kidney Injury}

4.1. Antibiotics. Antibiotics are a group of drugs used to treat various infections caused by bacteria and other microorganisms. The first antibiotic was discovered by Sir Alexander Fleming in 1928 in a significant breakthrough for medical science. The development of antibiotics is probably the largest advance in medicine in the 20th century and has saved millions of lives worldwide from infections such as TB.

Gentamicin is an aminoglycoside broad spectrum Gramnegative antibiotic which is routinely used in clinical practices for the treatment of Gram-negative infections alone or in synergy with beta-lactam antibiotics in adults, children, and neonates. Gentamicin use is however associated with significant nephrotoxicity-it is estimated that roughly $30 \%$ of patients receiving gentamicin for 30 days show some signs of renal impairment [82-84]. Gentamicin-induced nephrotoxicity is characterized by morphological alterations including destruction of cell organelles and necrosis, lysosomal swelling and mitochondrial vacuolisation preceding functional alterations marked by proteinuria, increased levels of serum urea and creatinine, which lead to acute kidney injury (AKI). The site of gentamicin nephrotoxic action is the kidney cortex, especially the proximal tubules. Animal models of aminoglycoside nephrotoxicity also present areas of interstitial fibrosis in the renal cortex and progressive tubular injury $[85,86]$.

Vancomycin is a cationic glycopeptide antibiotic used in the treatment of penicillin-resistant Gram-positive infections, methicillin-resistant Staphylococcus aureus infections, and Clostridium difficile infections, which has seen a resurgence in use due to the emergence of $\beta$-lactam-resistant Gram-positive organism-associated infections. Vancomycin is known to be both ototoxic and nephrotoxic [87], with vancomycin-induced nephrotoxicity reported to occur in up to $25 \%$ of patients $[88,89]$. Studies carried out in animal models showed increased urinary excretion of proximal tubule cells and in the activity of malate dehydrogenase (MDH) following vancomycin administration [90, 91]. Furthermore, a recent study also suggested that oxidative stress might underlie the pathogenesis of vancomycin-induced nephrotoxicity [92].

Acute kidney injury (AKI) is a common side effect of antibiotic therapy. However, given the diversity of the mechanisms of action of the most commonly used antibiotic therapies, it is perhaps not immediately clear whether this injury occurs as a result of a defined process. There is evidence however to implicate involvement of the MAPK signalling cascade in antibiotic-induced renal injury initiated by several distinct classes of antibiotics.

4.2. MAPK in Antibiotic-Induced Nephrotoxicity. A study carried out by Volpini et al. in 2006 showed that MAPKs may be involved in the pathogenesis of acute renal failure following gentamicin treatment [93]. Since there is evidence that both the MAPK and NF- $\kappa$ B systems can be activated by oxidative stress in gentamicin-treated animals, the expression of p-p38 MAPK and NF- $\kappa \mathrm{B}$ in the kidney during the evolution of tubulointerstitial nephritis and its relationship with histological features and renal function was investigated in gentamicin-treated rats in the presence or absence of an $\mathrm{NF}-\kappa \mathrm{B}$ inhibitor. Western blot analysis demonstrated the presence of the 43-kDa phosphorylated p38 MAPK and the $65-\mathrm{kDa} N F-\kappa \mathrm{B}$ proteins in the renal cortex from all treatment groups compared to control. The gentamicin-treated animals showed a greater p38 expression than the control and NF$\kappa \mathrm{B}$ inhibitor and gentamicin-treated animals. Data obtained in this study showed that p38 MAPK expression is increased during the development of gentamicin-induced interstitial nephritis and that such alteration is associated with enhancement of NF- $\kappa \mathrm{B}$ expression and the inflammatory process in the renal cortex, suggesting that the p38 MAPK pathway may be involved in the renal lesions induced by gentamicin [93]. Other studies verify this involvement of MAPK in antibioticassociated nephrotoxicity; p38-MAPK has been found to be upregulated in rat kidneys following gentamicin treatment, and it has been shown that combination treatment with the lipid-lowering drug, atorvastatin, ameliorated gentamicininduced nephrotoxicity, through inhibition of p38-MAPK and NF- $\kappa \mathrm{B}$ expression [94]. Previous studies have also demonstrated that the proliferative response observed after sublethal toxicant-induced renal injury may be mediated by activation of the MAPK signalling pathway, which is ultimately regulated by bioenergetic capacity [95-98].

A study carried out investigating the effects of vancomycin exposure in renal LLCPK 1 cells on cell proliferation showed a dose- and time-dependent increase in cell number and total cellular protein [99]. These effects were inhibited by pretreatment with a MAPK inhibitor, PD098059, preventing vancomycin-induced entry into the cell cycle, thus suggesting an association between the cell proliferative effects of vancomycin and the induction of MAPK signalling cascades [99].

\section{Calcineurin-Inhibitor-Induced Kidney Injury}

5.1. Calcineurin Inhibitors. In 1954, the first successful transplantation of a human kidney was performed between identical twins; the success of which was based on the lack of significant rejection between genetically identical 
twins, thus circumventing the requirement for immunosuppression [100]. Solid-organ transplantation was not truly implemented until the 1970s following significant technical and pharmacological advances, in particular, the discovery and development of the calcineurin inhibitors (CNIs) [101]. Despite the advances over the past four decades, the majority of renal allografts fail after a period of progressive functional decline which is associated with glomerulosclerosis, tubular atrophy, interstitial fibrosis, and arteriosclerosis, in a process referred to as chronic allograft injury (CAI) or chronic allograft nephropathy (CAN). The deterioration of renal allograft function and structure associated with CAI can occur due to immunological processes (i.e., chronic rejection) and/or a range of simultaneous nonimmunological factors such as CNI-induced nephrotoxicity, hypertension, and infection. The two most commonly employed immunosuppressants are the CNIs cyclosporine $\mathrm{A}(\mathrm{CsA})$ and tacrolimus (FK506).

CsA, also known as Sandimmune, is a 1203 dalton, lipophilic, cyclic compound, derived from fungal origins which was discovered in 1976. The first incidence of CsA employed as an immunosuppressant was in 1978, revolutionizing the field of organ transplantation [102]. CsA is primarily renowned as a powerful immunosuppressant for use in organ transplantation to prevent graft rejection in kidney, liver, heart, lung, and combined heart-lung transplants [103].

Tacrolimus, also known as FK506 or Prograf, is a $822 \mathrm{Da}, 23$-membered macrolide compound $\left(\mathrm{C}_{44} \mathrm{H}_{69} \mathrm{NO}_{12}\right)$ that was isolated from a soil microorganism Streptomyces tsukubaensis in Japan in 1984, [104, 105]. FK506 is a potent immunosuppressive agent employed worldwide since the early 1990s that is effective in allograft prophylaxis after organ transplantation, for therapy of acute rejection and in treatment of different immune diseases [106, 107]. In 2003, FK506 was used as initial immunosuppression in 67\% of kidney recipients and $89 \%$ of liver recipients (UNOS United Network for Organ Sharing 2004). FK506 is up to 100 times more potent than CsA [108], which has significantly reduced the incidence and severity of acute rejection rates in organ transplantation $[109,110]$.

Both CNIs follow similar molecular pathways, with both FK506 and CsA eventually inhibiting NFAT-dependent production of IL-2 and other cytokines and prevention of T-cell growth $[111,112]$. Recently, alternative molecular pathways have been identified for CsA, which has been found to inhibit the JNK and p38 signalling pathway activity triggered by antigen recognition in T cells (Figure 5) [113].

5.2. MAPK in CNI Nephrotoxicity. CsA and FK506 are widely used in transplant organ recipients, but in the kidney allograft, they may cause tubulointerstitial as well as mesangial fibrosis [114]. The fibrogenic effect of CNIs in the renal allograft is predominantly mediated by elevated intrarenal expression of TGF- $\beta[57,115]$, and subsequent excessive extracellular matrix (ECM) generation $[116,117]$. Using the rMC cell line, rat kidney mesangial cells, it has been shown that CsA and FK-506 induce an extremely rapid and dose-dependent increase of Y-Box-binding protein-1 (YB-1) content in a cell type-specific manner. The highly conserved YB-1 is a member of the family of cold-shock proteins with mitogenic properties which play a role in cellular stress responses and tumourigenesis and also controls TGF- $\beta 1$ translation in proximal tubular cells [118-120]. Given the fact that YB-1 is a downstream target of MAPK ERK1/2 [121, 122], the study continued to investigate the involvement of ERK1/2 in CsA-triggered cell activation. Previous studies have documented that YB-1 undergoes phosphorylation at serine $102\left(\mathrm{Ser}^{102}\right)$ by activated serine/threonine protein kinase Akt/protein kinase B $[114,123]$. Hanssen et al. showed that inhibition of Akt/ERK signals upstream of YB1 activation prevents its phosphorylation at Ser ${ }^{102}$ and abolishes the CsA-mediated YB-1 protein increase demonstrating that CsA-induced YB-1 accumulation was dependent on MAPK/ERK and PI3K/Akt signalling [124]. Hanssen et al. also verified these results in vivo, treating mice either with a vehicle control or CsA and analysing the renal YB1 content [124]. Immunoblotting indicated elevated YB-1 protein content in the CsA-treated mice, localised in the mesangial compartment [124].

\section{Cancer-Chemotherapeutic-Agent-Induced Kidney Injury}

6.1. Cancer Chemotherapeutic Agents. Chemotherapy continues to play a crucial role in the management of cancer, with the basic aim to kill cancerous cells whilst causing minimal damage to the other healthy cells in the body. Cancer chemotherapeutics are divided into different categories with several members in each category, including alkylating agents (e.g., cyclophosphamide); antimetabolites (e.g., methotrexate); plant alkaloids (e.g., etoposide); anthracyclines(e.g., doxirubicin); antitumor antibiotics (e.g., mitomycin C); platinum compounds (e.g., cisplatin); taxanes (e.g., taxol) [125]. Cancer chemotherapeutic agents can cause nephrotoxicity in various ways, with some drugs exerting immediate effects on renal function while others are known to have cumulative effects, causing renal injury after long periods of use [126]. Cisplatin is one of the most successful antineoplastic agents to date. It is used to treat a wide variety of solid tumours, and successful cure rates for certain cancers such as testicular cancer are as high as $90 \%$ following cisplatin treatment. One of the major limiting factors in the use of cisplatin however is development of acute kidney injury, with clinically measureable nephrotoxicity usually detected 10 days after administration. It is estimated that $20 \%$ of patients receiving high doses of cisplatin develop renal dysfunction [127]. The kidney is particularly susceptible to cisplatininduced toxicity due to the high concentration of the organic cation transporter 2 (OCT2), which is expressed mainly in the kidney and facilitates cellular entry of the cisplatin compound [128].

6.2. MAPK in Cisplatin-Induced Nephrotoxicity. The exact mechanisms governing cisplatin-induced nephrotoxicity are not completely understood; however, it is believed that MAPK plays a pivotal function. Indeed several studies both in 

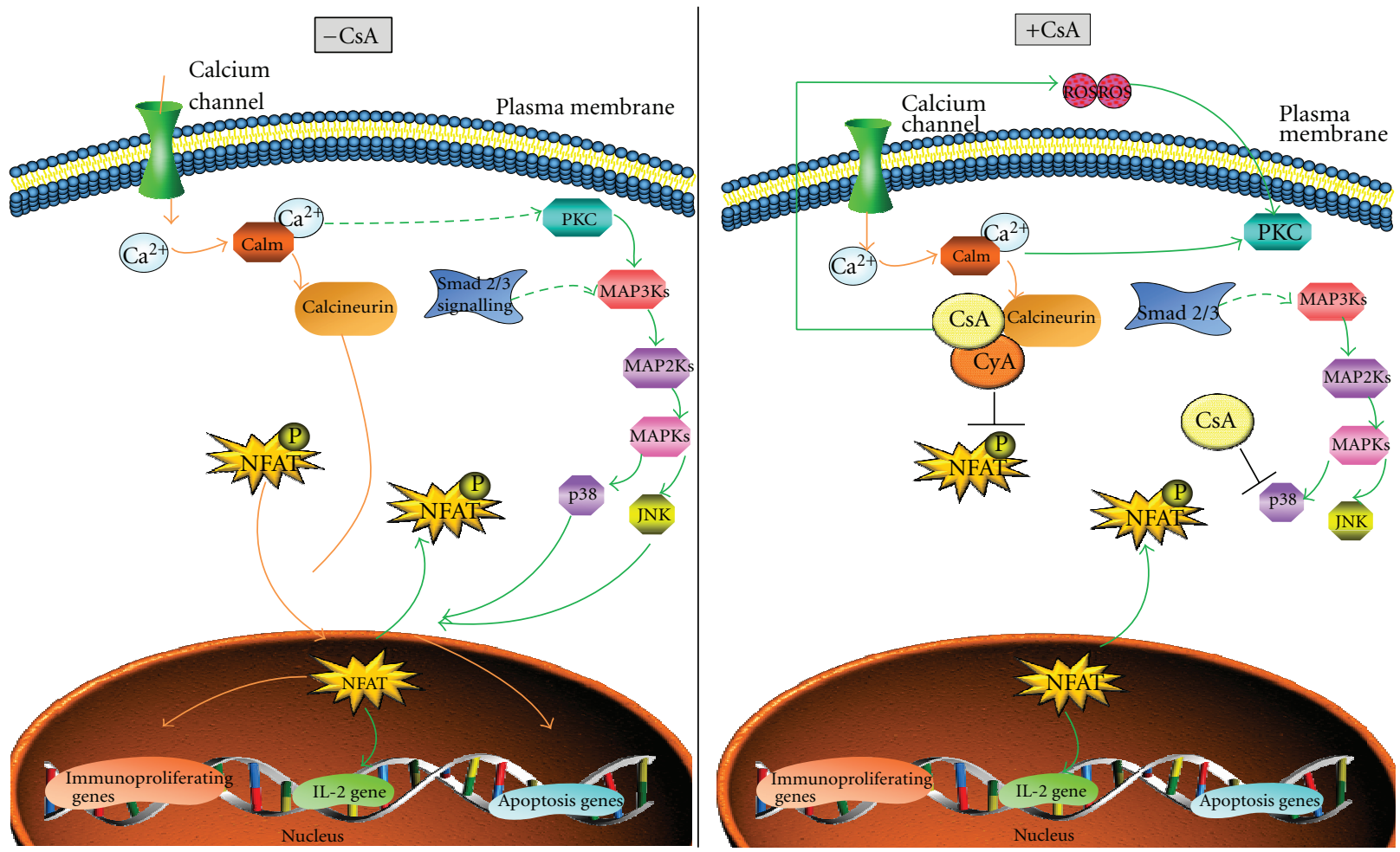

FIGURE 5: Alternative signaling in the presence of cyclosporine A. In normal, signaling calcineurin binds to and dephosphorylates NFAT, allowing it to enter the nucleus where it induces IL-2 expression. In the presence of cyclosporine this pathway is blocked by the binding of the cyclosporine/cyclophilin complex to calcineurin, which prevents the subsequent binding to NFAT. Alternative signaling occurs via the induction of a MAPK cascade, resulting in the expression of IL-2.

vitro and in vivo have shown that pharmacological inhibition of ERK1/2 ameliorates cisplatin-induced nephrotoxicity. There is conflicting evidence about the role that both p38 and JNK/SAPK play in cisplatin-induced kidney injury. Arany et al. [23] showed that ERK, and not p38 or JNK/SAPK inhibition, prevented cisplatin induced toxicity. However, other studies have shown that pharmacological inhibition of p38 both in vitro and in vivo prevented toxicity [129-131]. The role that JNK/SAPK plays in acute kidney injury following cisplatin exposure has been less well characterised; however, it has been shown that JNK/SAPK inhibition resulted in a significant reduction in cisplatin-induced nephrotoxicity in vivo [132].

A study by Pabla et al. identified PKC $\delta$ as a critical regulator of cisplatin nephrotoxicity, which can be effectively targeted for renoprotection during chemotherapy. The data showed that during cisplatin nephrotoxicity, Src interacted with, phosphorylated, and activated PKC $\delta$ in mouse kidney lysates. After activation, PKC $\delta$ regulated MAPKs, but not p53, to induce renal cell apoptosis. Thus, inhibition of PKC $\delta$, pharmacologically or genetically, attenuated kidney cell apoptosis and tissue damage, preserving renal function during cisplatin treatment. Conversely, inhibition of PKC $\delta$ enhanced cisplatin-induced cell death in multiple cancer cell lines and, remarkably, enhanced the chemotherapeutic effects of cisplatin in several xenograft and syngeneic mouse tumour models while protecting kidneys from nephrotoxicity. Together these results demonstrate a role of $\mathrm{PKC} \delta$ in cisplatin nephrotoxicity and support targeting $\mathrm{PKC} \delta$ as an effective strategy for renoprotection during cisplatin-based cancer therapy [133].

\section{Nonsteroidal Anti-Inflammatory Drug- (NSAID-) Induced Kidney Injury}

7.1. NSAIDS. The NSAID family includes several classes of drugs such as the carboxylic acids, for example, aspirin; acetic acids, for example, diclofenac; propionic acids, for example, ibuprofen and ketoprofen; and Cox-2 inhibitors, for example, celecoxib which are used worldwide as analgesics and antipyretics to combat pain, fever, and inflammation. They are especially effective for treating inflammatory diseases (e.g., arthritis) through nonspecific inhibition of cyclooxygenase (COX) enzymes which limits production of prostaglandins. Serious gastrointestinal side effects have been minimized with the advent of selective and specific COX2 inhibitors and misoprostol. However, the newer NSAIDs continue to be nephrotoxic much like the conventional NSAIDs [134]. The spectrum of nephrotoxicity includes acute tubular necrosis, acute tubulointerstitial nephritis, glomerulonephritis, renal papillary necrosis, chronic renal 
failure, salt and water retention, hypertension, and hyperkalaemia $[135,136]$.

7.2. MAPK in NSAID Nephrotoxicity. Hou et al. investigated the molecular basis of the renal injury by evaluating the expression of the stress marker, haeme oxygenase-1 (HO1), in celecoxib-stimulated glomerular mesangial cells [137]. Treatment with celecoxib resulted in concentration- and time-dependent increase of HO-1 expression. Conversely treatment with $\mathrm{N}$-acetylcysteine, a free radical scavenger, strongly decreased HO-1 expression, suggesting the involvement of reactive oxygen species (ROS). Following treatment with various MAPK inhibitors, the study showed that only a specific JNK inhibitor attenuated celecoxib-induced HO1 expression, and kinase assays demonstrated increased phosphorylation and activation of c-JNK following NSAID treatment [137]. The presence of a free radical scavenger reduced the stimulatory effect of celecoxib on stress kinase activities, suggesting an involvement of JNK in HO-1 expression. Treatment with a PI-3K specific inhibitor prevented the enhancement of HO-1 expression, which correlated with inhibition of the phosphorylation of the PDK-1 downstream substrate Akt/protein kinase B (PKB). The data presented in this study suggested that celecoxib-induced $\mathrm{HO}-1$ expression in glomerular mesangial cells may be mediated by ROS via the JNK-PI-3K cascade [137].

\section{Conclusion}

The complex nature of critical illness often necessitates the use of multiple therapeutic agents, many of which may individually or in combination have the potential to cause kidney injury. Accordingly, the incidence of drug-induced nephrotoxicity is rapidly increasing [138]. Drugs known to cause nephrotoxicity have been shown to exert their toxic effects through one or more common pathogenic mechanisms [139]. It is important to appreciate that a single drug causing renal toxicity can involve multiple pathophysiological pathways and that predisposing factors are common to virtually all causative agents mediating kidney injury. Various studies, both in vitro and in vivo, have shown that the administration of certain drugs acts as the stimulus to trigger various MAPK cascades, thus mediating cellular responses to kidney injury [139]. Indeed, activation of these central pathways is evidenced in both acute and chronic kidney injury. Data from renal biopsies in humans have shown upregulation of MAPKs in a variety of renal conditions, suggesting involvement in human renal disease, and may provide a new target for intervention. Interventions aimed at providing renoprotection, such as ACE-inhibition or statin therapy, can reduce the renal MAPK expression, suggesting that increased renal MAPK expression is involved in the pathophysiology of kidney damage. The use of specific MAPK inhibitors has further elucidated this role. Animal data presented in this paper suggests that MAPK inhibition may be of use in acute inflammatory renal disorders, and in chronic conditions characterized by fibrosis. In order to explore the potential of MAPKs as a novel intervention strategy in kidney disease, it is important to establish the renal conditions that can specifically benefit from MAPK inhibition, since studies have shown that not all conditions can be improved through inhibition of the MAPK signalling cascade [24]. However, since the MAPK cascades have been implicated in numerous studies in the development of kidney damage and disease, continued research in this area will hopefully highlight novel therapies or mechanisms of prevention of kidney injury.

\section{References}

[1] C. Widmann, S. Gibson, M. B. Jarpe, and G. L. Johnson, "Mitogen-activated protein kinase: conservation of a threekinase module from yeast to human," Physiological Reviews, vol. 79, no. 1, pp. 143-180, 1999.

[2] G. L. Johnson and R. Lapadat, "Mitogen-activated protein kinase pathways mediated by ERK, JNK, and p38 protein kinases," Science, vol. 298, no. 5600, pp. 1911-1912, 2002.

[3] W. Ligterink and H. Hirt, "Mitogen-activated protein (MAP) kinase pathways in plants: versatile signaling tools," International Review of Cytology, vol. 201, pp. 209-275, 2000.

[4] D. B. Sacks, "The role of scaffold proteins in MEK/ERK signalling," Biochemical Society Transactions, vol. 34, no. 5, pp. 833-836, 2006.

[5] P. P. Roux and J. Blenis, "ERK and p38 MAPK-activated protein kinases: a family of protein kinases with diverse biological functions," Microbiology and Molecular Biology Reviews, vol. 68, no. 2, pp. 320-344, 2004.

[6] R. J. Orton, O. E. Sturm, V. Vyshemirsky, M. Calder, D. R. Gilbert, and W. Kolch, "Computational modelling of the receptor-tyrosine-kinase-activated MAPK pathway," Biochemical Journal, vol. 392, no. 2, pp. 249-261, 2005.

[7] I. Wortzel and R. Seger, "The ERK cascade: distinct functions within various subcellular organelles," Genes and Cancer, vol. 2, no. 3, pp. 195-209, 2011.

[8] H. Rubinfeld and R. Seger, "The ERK cascade: a prototype of MAPK signaling," Molecular Biotechnology, vol. 31, no. 2, pp. 151-174, 2005.

[9] M. Raman, W. Chen, and M. H. Cobb, "Differential regulation and properties of MAPKs," Oncogene, vol. 26, no. 22, pp. 3100-3112, 2007.

[10] Y. Keshet and R. Seger, "The MAP kinase signaling cascades: a system of hundreds of components regulates a diverse array of physiological functions," Methods in Molecular Biology, vol. 661, pp. 3-38, 2010.

[11] J. Pouyssegur, "Signal transduction. An arresting start for MAPK," Science, vol. 290, no. 5496, pp. 1515-1518, 2000.

[12] J. A. Cooper, B. M. Sefton, and T. Hunter, "Diverse mitogenic agents induce the phosphorylation of two related 42,000dalton proteins on tyrosine in quiescent chick cells," Molecular and Cellular Biology, vol. 4, no. 1, pp. 30-37, 1984.

[13] T. G. Boulton, S. H. Nye, D. J. Robbins et al., "ERKs: a family of protein-serine/threonine kinases that are activated and tyrosine phosphorylated in response to insulin and NGF," Cell, vol. 65, no. 4, pp. 663-675, 1991.

[14] B. Derijard, J. Raingeaud, T. Barrett et al., "Independent human MAP kinase signal transduction pathways defined by MEK and MKK isoforms," Science, vol. 267, no. 5198, pp. 682-685, 1995.

[15] B. Derijard, M. Hibi, I. H. Wu et al., "JNK1: a protein kinase stimulated by UV light and Ha-Ras that binds and 
phosphorylates the c-Jun activation domain," Cell, vol. 76, no. 6, pp. 1025-1037, 1994.

[16] T. W. Sturgill, L. B. Ray, E. Erikson, and J. L. Maller, "Insulinstimulated MAP-2 kinase phosphorylates and activates ribosomal protein S6 kinase II," Nature, vol. 334, no. 6184, pp. 715-718, 1988.

[17] L. Chang and M. Karin, "Mammalian MAP kinase signalling cascades," Nature, vol. 410, no. 6824, pp. 37-40, 2001.

[18] G. Pearson, F. Robinson, T. B. Gibson et al., "Mitogenactivated protein (MAP) kinase pathways: regulation and physiological functions," Endocrine Reviews, vol. 22, no. 2, pp. 153-183, 2001.

[19] B. K. Brott, A. Alessandrini, D. A. Largaespada et al., "MEK2 is a kinase related to MEK1 and is differentially expressed in murine tissues," Cell Growth and Differentiation, vol. 4, no. 11, pp. 921-930, 1993.

[20] C. F. Zheng and K. L. Guan, "Cloning and characterization of two distinct human extracellular signal- regulated kinase activator kinases, MEK1 and MEK2," Journal of Biological Chemistry, vol. 268, no. 15, pp. 11435-11439, 1993.

[21] S. E. Egan and R. A. Weinberg, "The pathway to signal achievement," Nature, vol. 365, no. 6449, pp. 781-783, 1993.

[22] S. Omori, M. Hida, H. Fujita et al., "Extracellular signalregulated kinase inhibition slows disease progression in mice with polycystic kidney disease," Journal of the American Society of Nephrology, vol. 17, no. 6, pp. 1604-1614, 2006.

[23] I. Arany, J. K. Megyesi, H. Kaneto, P. M. Price, and R. L. Safirstein, "Cisplatin-induced cell death is EGFR/src/ERK signaling dependent in mouse proximal tubule cells," American Journal of Physiology, vol. 287, no. 3, pp. F543-F549, 2004.

[24] J. W. Pippin, R. Durvasula, A. Petermann, K. Hiromura, W. G. Couser, and S. J. Shankland, "DNA damage is a novel response to sublytic complement C5b-9-induced injury in podocytes," Journal of Clinical Investigation, vol. 111, no. 6, pp. 877-885, 2003.

[25] E. Pelliccia, C. Falchi, G. Angelotti, and M. Lombardi, "Postoperative analgesia with peridural morphine. Comparative study in thoracic and abdominal surgery," Minerva Anestesiologica, vol. 54, no. 12, pp. 521-524, 1988.

[26] T. Smeal, B. Binetruy, D. Mercola et al., "Oncoproteinmediated signalling cascade stimulates c-Jun activity by phosphorylation of serines 63 and 73," Molecular and Cellular Biology, vol. 12, no. 8, pp. 3507-3513, 1992.

[27] T. Kallunki, B. Su, I. Tsigelny et al., "JNK2 contains a specificity-determining region responsible for efficient c-Jun binding and phosphorylation," Genes and Development, vol. 8, no. 24, pp. 2996-3007, 1994.

[28] M. J. Czaja, "The future of GI and liver research: editorial perspectives III. JNK/AP-1 regulation of hepatocyte death," American Journal of Physiology, vol. 284, no. 6, pp. G875G879, 2003.

[29] A. Lin, A. Minden, H. Martinetto et al., "Identification of a dual specificity kinase that activates the Jun kinases and p38Mpk2," Science, vol. 268, no. 5208, pp. 286-290, 1995.

[30] A. Minden, A. Lin, M. McMahon et al., "Differential activation of ERK and JNK mitogen-activated protein kinases by Raf-1 and MEKK," Science, vol. 266, no. 5191, pp. 17191723, 1994.

[31] F. Y. Ma, J. Liu, and D. J. Nikolic-Paterson, "The role of stressactivated protein kinase signaling in renal pathophysiology," Brazilian Journal of Medical and Biological Research, vol. 42, no. 1, pp. 29-37, 2009.
[32] C. M. Pombo, J. V. Bonventre, J. Avruch, J. R. Woodgett, J. M. Kyriakis, and T. Force, "The stress-activated protein kinases are major c-Jun amino-terminal kinases activated by ischemia and reperfusion," Journal of Biological Chemistry, vol. 269, no. 42, pp. 26546-26551, 1994.

[33] M. H. De Borst, J. Prakash, W. B. W. H. Melenhorst et al., "Glomerular and tubular induction of the transcription factor c-Jun in human renal disease," Journal of Pathology, vol. 213, no. 2, pp. 219-228, 2007.

[34] R. S. Flanc, F. Y. Ma, G. H. Tesch et al., "A pathogenic role for JNK signaling in experimental anti-GBM glomerulonephritis," Kidney International, vol. 72, no. 6, pp. 698-708, 2007.

[35] F. Y. Ma, R. S. Flanc, G. H. Tesch et al., "A pathogenic role for c-Jun amino-terminal kinase signaling in renal fibrosis and tubular cell apoptosis," Journal of the American Society of Nephrology, vol. 18, no. 2, pp. 472-484, 2007.

[36] J. Kanellis, F. Y. Ma, R. Kandane-Rathnayake et al., "JNK signalling in human and experimental renal ischaemia/ reperfusion injury," Nephrology Dialysis Transplantation, vol. 25, no. 9, pp. 2898-2908, 2010.

[37] J. L. Brewster, T. De Valoir, N. D. Dwyer, E. Winter, and M. C. Gustin, "An osmosensing signal transduction pathway in yeast," Science, vol. 259, no. 5102, pp. 1760-1763, 1993.

[38] J. Raingeaud, S. Gupta, J. S. Rogers et al., "Pro-inflammatory cytokines and environmental stress cause p38 mitogenactivated protein kinase activation by dual phosphorylation on tyrosine and threonine," Journal of Biological Chemistry, vol. 270, no. 13, pp. 7420-7426, 1995.

[39] C. S. Patil and K. L. Kirkwood, "P38 MAPK signaling in oralrelated diseases," Journal of Dental Research, vol. 86, no. 9, pp. 812-825, 2007.

[40] H. Iwasa, J. Han, and F. Ishikawa, "Mitogen-activated protein kinase p38 defines the common senescence-signalling pathway," Genes to Cells, vol. 8, no. 2, pp. 131-144, 2003.

[41] W. Wang, J. X. Chen, R. Liao et al., "Sequential activation of the MEK-extracellular signal-regulated kinase and MKK3/6p38 mitogen-activated protein kinase pathways mediates oncogenic ras-induced premature senescence," Molecular and Cellular Biology, vol. 22, no. 10, pp. 3389-3403, 2002.

[42] Q. Deng, R. Liao, B. L. Wu, and P. Sun, "High intensity ras signaling induces premature senescence by activating p 38 pathway in primary human fibroblasts," Journal of Biological Chemistry, vol. 279, no. 2, pp. 1050-1059, 2004.

[43] K. Ono and J. Han, "The p38 signal transduction pathway activation and function," Cellular Signalling, vol. 12, no. 1, pp. 1-13, 2000.

[44] J. Zhang, B. Shen, and A. Lin, "Novel strategies for inhibition of the p38 MAPK pathway," Trends in Pharmacological Sciences, vol. 28, no. 6, pp. 286-295, 2007.

[45] J. P. Coppé, C. K. Patil, F. Rodier et al., "Senescence-associated secretory phenotypes reveal cell-nonautonomous functions of oncogenic RAS and the p53 tumor suppressor," PLoS Biology, vol. 6, no. 12, article e301, pp. 2853-2868, 2008.

[46] F. Rodier, J. Campisi, and D. Bhaumik, "Two faces of p53: aging and tumor suppression," Nucleic Acids Research, vol. 35, no. 22, pp. 7475-7484, 2007.

[47] A. Freund, C. K. Patil, and J. Campisi, "P38MAPK is a novel DNA damage response-independent regulator of the senescence-associated secretory phenotype," EMBO Journal, vol. 30, no. 8, pp. 1536-1548, 2011.

[48] Y. Iwata, T. Wada, K. Furuichi et al., "p38 mitogen-activated protein kinase contributes to autoimmune renal injury in MRL-Faslpr mice," Journal of the American Society of Nephrology, vol. 14, no. 1, pp. 57-67, 2003. 
[49] C. Stambe, R. C. Atkins, G. H. Tesch et al., "Blockade of p38 $\alpha$ MAPK ameliorates acute inflammatory renal injury in rat anti-GBM glomerulonephritis," Journal of the American Society of Nephrology, vol. 14, no. 2, pp. 338-351, 2003.

[50] V. Jullien-Flores, O. Dorseuil, F. Romero et al., "Bridging Ral GTPase to Rho pathways. RLIP76, a Ral effector with CDC42/Rac GTPase-activating protein activity," Journal of Biological Chemistry, vol. 270, no. 38, pp. 22473-22477, 1995.

[51] Z. S. Zhao, T. Leung, E. Manser, and L. Lim, "Pheromone signalling in Saccharomyces cerevisiae requires the small GTP- binding protein Cdc42p and its activator CDC24," Molecular and Cellular Biology, vol. 15, no. 10, pp. 5246-5257, 1995.

[52] S. Zhang, J. Han, M. A. Sells et al., "Rho family GTPases regulate p38 mitogen-activated protein kinase through the downstream mediator Pak1," Journal of Biological Chemistry, vol. 270, no. 41, pp. 23934-23936, 1995.

[53] C. M. Pombo, J. H. Kehrl, I. Sanchez et al., "Activation of the SAPK pathway by the human STE20 homologue germinal centre kinase," Nature, vol. 377, no. 6551, pp. 750-754, 1995.

[54] S. Marcus, A. Polverino, M. Barr, and M. Wigler, "Complexes between STE5 and components of the pheromoneresponsive mitogen-activated protein kinase module," Proceedings of the National Academy of Sciences of the United States of America, vol. 91, no. 16, pp. 7762-7766, 1994.

[55] C. S. Hill and R. Treisman, "Transcriptional regulation by extracellular signals: mechanisms and specificity," Cell, vol. 80, no. 2, pp. 199-211, 1995.

[56] E. Manser, T. Leung, H. Salihuddin, Z. S. Zhao, and L. Lim, "A brain serine/threonine protein kinase activated by Cdc42 and Rac1," Nature, vol. 367, no. 6458, pp. 40-46, 1994.

[57] B. Geiger, A. Bershadsky, R. Pankov, and K. M. Yamada, "Transmembrane extracellular matrix-cytoskeleton crosstalk," Nature Reviews Molecular Cell Biology, vol. 2, no. 11, pp. 793-805, 2001.

[58] S. Anderson, L. DiCesare, I. Tan, T. Leung, and N. Sundarraj, "Rho-mediated assembly of stress fibers is differentially regulated in corneal fibroblasts and myofibroblasts," Experimental Cell Research, vol. 298, no. 2, pp. 574-583, 2004.

[59] J. E. Darnell Jr., I. M. Kerr, and G. R. Stark, "Jak-STAT pathways and transcriptional activation in response to IFNs and other extracellular signaling proteins," Science, vol. 264, no. 5164, pp. 1415-1421, 1994.

[60] R. Marais, J. Wynne, and R. Treisman, “The SRF accessory protein Elk-1 contains a growth factor-regulated transcriptional activation domain," Cell, vol. 73, no. 2, pp. 381-393, 1993.

[61] R. A. Hipskind, D. Buscher, A. Nordheim, and M. Baccarini, "Ras/MAP kinase-dependent and -independent signaling pathways target distinct ternary complex factors," Genes and Development, vol. 8, no. 15, pp. 1803-1816, 1994.

[62] K. Y. Choi, B. Satterberg, D. M. Lyons, and E. A. Elion, "Ste5 tethers multiple protein kinases in the MAP kinase cascade required for mating in S. cerevisiae," Cell, vol. 78, no. 3, pp. 499-512, 1994.

[63] J. M. Rodier, A. M. Valles, M. Denoyelle, J. P. Thiery, and B. Boyer, "pp60(c-src) Is a positive regulator of growth factorinduced cell scattering in a rat bladder carcinoma cell line," Journal of Cell Biology, vol. 131, no. 3, pp. 761-773, 1995.

[64] J. T. Parsons and M. J. Weber, "Genetics of src: structure and functional organization of a protein tyrosine kinase," Current Topics in Microbiology and Immunology, vol. 147, pp. 79-127, 1989.
[65] R. B. Irby and T. J. Yeatman, "Role of Src expression and activation in human cancer," Oncogene, vol. 19, no. 49, pp. 5636-5642, 2000.

[66] S. L. Warren, L. M. Handel, and W. J. Nelson, "Elevated expression of pp60c-src alters a selective morphogenetic property of epithelial cells in vitro without a mitogenic effect," Molecular and Cellular Biology, vol. 8, no. 2, pp. 632646, 1988.

[67] T. Volberg, B. Geiger, R. Dror, and Y. Zick, "Modulation of intercellular adherens-type junctions and tyrosine phosphorylation of their components in RSV-transformed cultured chick lens cells," Cell regulation, vol. 2, no. 2, pp. 105-120, 1991.

[68] D. K. Luttrell, L. M. Luttrell, and S. J. Parsons, "Augmented mitogenic responsiveness to epidermal growth factor in murine fibroblasts that overexpress pp60c-src," Molecular and Cellular Biology, vol. 8, no. 1, pp. 497-501, 1988.

[69] S. Roche, M. Koegl, M. V. Barone, M. F. Roussel, and S. A. Courtneidge, "DNA synthesis induced by some but not all growth factors requires Src family protein tyrosine kinases," Molecular and Cellular Biology, vol. 15, no. 2, pp. 1102-1109, 1995.

[70] S. M. Thomas, P. Soriano, and A. Imamoto, "Specific and redundant roles of Src and Fyn in organizing the cytoskeleton," Nature, vol. 376, no. 6537, pp. 267-271, 1995.

[71] B. Boyer, S. Roche, M. Denoyelle, and J. P. Thiery, "Src and Ras are involved in separate pathways in epithelial cell scattering," EMBO Journal, vol. 16, no. 19, pp. 5904-5913, 1997.

[72] E. A. Clark and J. S. Brugge, "Redistribution of activted pp60(c-src) to integrin-dependent cytoskeletal complexes in thrombin-stimulated platelets," Molecular and Cellular Biology, vol. 13, no. 3, pp. 1863-1871, 1993.

[73] S. Kellie, A. R. Horvath, and M. A. Elmore, "Cytoskeletal targets for oncogenic tyrosine kinases," Journal of Cell Science, vol. 99, no. 2, pp. 207-211, 1991.

[74] H. Okamura and M. D. Resh, "p80/85 Cortactin associates with the Src SH2 domain and colocalizes with $\mathrm{v}$-Src in transformed cells," Journal of Biological Chemistry, vol. 270, no. 44, pp. 26613-26618, 1995.

[75] H. Wu, A. B. Reynolds, S. B. Kanner, R. R. Vines, and J. T. Parsons, "Identification and characterization of a novel cytoskeleton-associated pp60(src) substrate," Molecular and Cellular Biology, vol. 11, no. 10, pp. 5113-5124, 1991.

[76] M. V. Barone and S. A. Courtneidge, "Myc but not Fos rescue of PDGF signalling block caused by kinase-inactive Src," Nature, vol. 378, no. 6556, pp. 509-512, 1995.

[77] J. McGlade, A. Cheng, G. Pelicci, P. G. Pelicci, and T. Pawson, "Shc proteins are phosphorylated and regulated by the vSrc and v-Fps protein-tyrosine kinases," Proceedings of the National Academy of Sciences of the United States of America, vol. 89, no. 19, pp. 8869-8873, 1992.

[78] K. Nagai, M. Takata, H. Yamamura, and T. Kurosaki, “Tyrosine phosphorylation of Shc is mediated through Lyn and Syk in B cell receptor signaling," Journal of Biological Chemistry, vol. 270, no. 12, pp. 6824-6829, 1995.

[79] M. Takikita-Suzuki, M. Haneda, M. Sasahara et al., "Activation of Src kinase in platelet-derived growth factor-Bdependent tubular regeneration after acute ischemic renal injury," American Journal of Pathology, vol. 163, no. 1, pp. 277-286, 2003. 
[80] D. M. Townsend, K. D. Tew, L. He, J. B. King, and M. H. Hanigan, "Role of glutathione S-transferase Pi in cisplatininduced nephrotoxicity," Biomedicine and Pharmacotherapy, vol. 63, no. 2, pp. 79-85, 2009.

[81] A. Yonezawa and K. I. Inui, "Organic cation transporter OCT/SLC22A and H+/organic cation antiporter MATE/ SLC47A are key molecules for nephrotoxicity of platinum agents," Biochemical Pharmacology, vol. 81, no. 5, pp. 563568, 2010 .

[82] J. M. Prins, G. J. Weverling, K. De Blok, R. J. Van Ketel, and P. Speelman, "Validation and nephrotoxicity of a simplified once-daily aminoglycoside dosing schedule and guidelines for monitoring therapy," Antimicrobial Agents and Chemotherapy, vol. 40, no. 11, pp. 2494-2499, 1996.

[83] M. Barza, J. P. A. Ioannidis, J. C. Cappelleri, and J. Lau, "Single or multiple daily doses of aminoglycosides: a metaanalysis," British Medical Journal, vol. 312, no. 7027, pp. 338345, 1996.

[84] B. H. Ali, "The effect of Nigella sativa oil on gentamicin nephrotoxicity in rats," American Journal of Chinese Medicine, vol. 32, no. 1, pp. 49-55, 2004.

[85] D. C. Houghton, D. Lee, D. N. Gilbert, and W. M. Bennett, "Chronic gentamicin nephrotoxicity: continued tubular injury with preserved glomerular filtration function," American Journal of Pathology, vol. 123, no. 1, pp. 183-194, 1986.

[86] D. C. Houghton, J. English, and W. M. Bennett, "Chronic tubulointerstitial nephritis and renal insufficiency associated with long-term "subtherapeutic" gentamicin," Journal of Laboratory and Clinical Medicine, vol. 112, no. 6, pp. 694703, 1988.

[87] R. S. Griffith, "Introduction to vancomycin," Reviews of Infectious Diseases, vol. 3, pp. S200-S204, 1981.

[88] T. E. Welty and A. K. Copa, "Impact of vancomycin therapeutic drug monitoring on patient care," Annals of Pharmacotherapy, vol. 28, no. 12, pp. 1335-1339, 1994.

[89] T. Iwamoto, Y. Kagawa, and M. Kojima, "Clinical efficacy of therapeutic drug monitoring in patients receiving vancomycin," Biological and Pharmaceutical Bulletin, vol. 26, no. 6, pp. 876-879, 2003.

[90] R. Marre, E. Schulz, T. Anders, and K. Sack, "Renal tolerance and pharmacokinetics of vancomycin in rats," Journal of Antimicrobial Chemotherapy, vol. 14, no. 3, pp. 253-260, 1984.

[91] G. B. Appel, D. B. Given, L. R. Levine, and G. L. Cooper, "Vancomycin and the kidney," American Journal of Kidney Diseases, vol. 8, no. 2, pp. 75-80, 1986.

[92] Y. Nishino, S. Takemura, Y. Minamiyama et al., "Targeting superoxide dismutase to renal proximal tubule cells attenuates vancomycin-induced nephrotoxicity in rats," Free Radical Research, vol. 37, no. 4, pp. 373-379, 2003.

[93] R. A. Volpini, A. P. C. Balbi, R. S. Costa, and T. M. Coimbra, "Increased expression of p38 mitogen-activated protein kinase is related to the acute renal lesions induced by gentamicin," Brazilian Journal of Medical and Biological Research, vol. 39, no. 6, pp. 817-823, 2006.

[94] E. Ozbek, M. Cekmen, Y. O. Ilbey, A. Simsek, E. C. Polat, and A. Somay, "Atorvastatin prevents gentamicin-induced renal damage in rats through the inhibition of p38-MAPK and NFkB pathways," Renal Failure, vol. 31, no. 5, pp. 382-392, 2009.

[95] R. Safirstein, J. DiMari, J. Meavesi, and P. Price, "Mechanisms of renal repair and survival following acute injury," Seminars in Nephrology, vol. 18, no. 5, pp. 519-522, 1998.
[96] T. Yano, Y. Yano, M. Yuasa et al., "The repetitive activation of extracellular signal-regulated kinase is required for renal regeneration in rat," Life Sciences, vol. 62, no. 25, pp. 23412347, 1998.

[97] F. Roger, P. Y. Martin, M. Rousselot, H. Favre, and E. Féraille, "Cell shrinkage triggers the activation of mitogen-activated protein kinases by hypertonicity in the rat kidney medullary thick ascending limb of the Henle's loop. Requirement of p38 kinase for the regulatory volume increase response," Journal of Biological Chemistry, vol. 274, no. 48, pp. 34103-34110, 1999.

[98] J. F. Di Mari, R. Davis, and R. L. Safirstein, "MAPK activation determines renal epithelial cell survival during oxidative injury," American Journal of Physiology, vol. 277, no. 2, pp. F195-F203, 1999.

[99] D. W. King and M. A. Smith, "Proliferative responses observed following vancomycin treatment in renal proximal tubule epithelial cells," Toxicology in Vitro, vol. 18, no. 6, pp. 797-803, 2004.

[100] J. P. Merrill, J. E. Murray, J. H. Harrison, and W. R. Guild, "Successful homotransplantation of the human kidney between identical twins," Journal of the American Medical Association, vol. 160, no. 4, pp. 277-282, 1956.

[101] S. O'Connell, C. Slattery, M. P. Ryan, and T. McMorrow, "Identification of novel indicators of cyclosporine A nephrotoxicity in a CD-1 mouse model," Toxicology and Applied Pharmacology, vol. 252, no. 2, pp. 201-210, 2011.

[102] R. Y. Calne, "The current state of renal transplantation," Kidney International, vol. 29, no. 19, pp. S23-S24, 1986.

[103] C. Li, C. W. Yang, W. Y. Kim et al., "Reversibility of chronic cyclosporine nephropathy in rats after withdrawal of cyclosporine," American Journal of Physiology, vol. 284, no. 2, pp. F389-F398, 2003.

[104] U. Christians, F. Braun, M. Schmidt et al., "Specific and sensitive measurement of FK506 and its metabolites in blood and urine of liver-graft recipients," Clinical Chemistry, vol. 38, no. 10, pp. 2025-2032, 1992.

[105] T. Kino and T. Goto, "Discovery of FK-506 and update," Annals of the New York Academy of Sciences, vol. 685, pp. 1321, 1993.

[106] A. Lampen, U. Christians, F. P. Guengerich et al., "Metabolism of the immunosuppressant tacrolimus in the small intestine: cytochrome P450, drug interactions, and interindividual variability," Drug Metabolism and Disposition, vol. 23, no. 12, pp. 1315-1324, 1995.

[107] J. Pratschke, T. Steinmüller, W. O. Bechstein et al., "Orthotopic liver transplantation for hepatic associated metabolic disorders," Clinical Transplantation, vol. 12, no. 3, pp. 228232, 1998.

[108] S. Goto, S. M. Stepkowski, and B. D. Kahan, "Effect of FK 506 and cyclosporine on heart allograft survival in rats," Transplantation Proceedings, vol. 23, no. 1 I, pp. 529-530, 1991.

[109] B. Kaplan, J. D. Schold, and H. U. Meier-Kriesche, "Longterm graft survival with neoral and tacrolimus: a paired kidney analysis," Journal of the American Society of Nephrology, vol. 14, no. 11, pp. 2980-2984, 2003.

[110] H. Töz, S. Şen, M. Seziş et al., "Comparison of tacrolimus and cyclosporin in renal transplantation by the protocol biopsies," Transplantation Proceedings, vol. 36, no. 1, pp. 134136, 2004.

[111] D. A. Fruman, C. B. Klee, B. E. Bierer, and S. J. Burakoff, "Calcineurin phosphatase activity in T lymphocytes is inhibited 
by FK 506 and cyclosporin A," Proceedings of the National Academy of Sciences of the United States of America, vol. 89, no. 9, pp. 3686-3690, 1992.

[112] M. Kronke, W. J. Leonard, and J. M. Depper, "Cyclosporin A inhibits T-cell growth factor gene expression at the level of mRNA transcription," Proceedings of the National Academy of Sciences of the United States of America, vol. 81, no. 16 I, pp. 5214-5218, 1984.

[113] S. Matsuda, F. Shibasaki, K. Takehana, H. Mori, E. Nishida, and S. Koyasu, "Two distinct action mechanisms of immunophilin-ligand complexes for the blockade of T-cell activation," EMBO Reports, vol. 1, no. 5, pp. 428-434, 2000.

[114] B. W. Sutherland, J. Kucab, J. Wu et al., "Akt phosphorylates the Y-box binding protein 1 at Ser102 located in the cold shock domain and affects the anchorage-independent growth of breast cancer cells," Oncogene, vol. 24, no. 26, pp. 42814292, 2005.

[115] F. S. Shihab, T. F. Andoh, A. M. Tanner, and W. M. Bennett, "Sodium depletion enhances fibrosis and the expression of TGF- $\beta 1$ and matrix proteins in experimental chronic cyclosporine nephropathy," American Journal of Kidney Diseases, vol. 30, no. 1, pp. 71-81, 1997.

[116] R. A. Ignotz and J. Massague, "Transforming growth factor$\beta$ stimulates the expression of fibronectin and collagen and their incorporation into the extracellular matrix," Journal of Biological Chemistry, vol. 261, no. 9, pp. 4337-4345, 1986.

[117] H. W. Schnaper, T. Hayashida, S. C. Hubchak, and A. C. Poncelet, "TGF- $\beta$ signal transduction and mesangial cell fibrogenesis," American Journal of Physiology, vol. 284, no. 2, pp. F243-F252, 2003.

[118] Z. H. Lu, J. T. Books, and T. J. Ley, "YB-1 is important for late-stage embryonic development, optimal cellular stress responses, and the prevention of premature senescence," Molecular and Cellular Biology, vol. 25, no. 11, pp. 4625-4637, 2005.

[119] B. Schittek, K. Psenner, B. Sauer, F. Meier, T. Iftner, and C. Garbe, "The increased expression of Y box-binding protein 1 in melanoma stimulates proliferation and tumor invasion, antagonizes apoptosis and enhances chemoresistance," International Journal of Cancer, vol. 120, no. 10, pp. 2110-2118, 2007.

[120] D. J. Fraser, A. O. Phillips, X. Zhang et al., "Y-box protein1 controls transforming growth factor- $\beta 1$ translation in proximal tubular cells," Kidney International, vol. 73, no. 6, pp. 724-732, 2008.

[121] L. S. Coles, L. Lambrusco, J. Burrows et al., "Phosphorylation of cold shock domain/Y-box proteins by ERK2 and GSK3 $\beta$ and repression of the human VEGF promoter," FEBS Letters, vol. 579, no. 24, pp. 5372-5378, 2005.

[122] A. L. Stratford, C. J. Fry, C. Desilets et al., "Y-box binding protein-1 serine 102 is a downstream target of $\mathrm{p} 90$ ribosomal S6 kinase in basal-like breast cancer cells," Breast Cancer Research, vol. 10, no. 6, article R99, 2008.

[123] V. Evdokimova, P. Ruzanov, M. S. Anglesio et al., "Aktmediated YB-1 phosphorylation activates translation of silent mRNA species," Molecular and Cellular Biology, vol. 26, no. 1, pp. 277-292, 2006.

[124] L. Hanssen, B. C. Frye, T. Ostendorf et al., "Y-box binding protein-1 mediates profibrotic effects of calcineurin inhibitors in the kidney," Journal of Immunology, vol. 187, no. 1, pp. 298-308, 2011.
[125] E. Chu and V. T. Devita Jr., Eds., Physicians' Cancer Chemotherapy Drug Manual 2001, Jones and Bartlett Publishers, London, UK, 2001.

[126] N. J. Vogelzang, "Nephrotoxicity from chemotherapy: prevention and management," Oncology, vol. 5, no. 10, pp. 97105, 1991.

[127] X. Yao, K. Panichpisal, N. Kurtzman, and K. Nugent, "Cisplatin nephrotoxicity: a review," American Journal of the Medical Sciences, vol. 334, no. 2, pp. 115-124, 2007.

[128] R. Kröning, A. K. Lichtenstein, and G. T. Nagami, "Sulfurcontaining amino acids decrease cisplatin cytotoxicity and uptake in renal tubule epithelial cell lines," Cancer Chemotherapy and Pharmacology, vol. 45, no. 1, pp. 43-49, 2000.

[129] G. Ramesh and W. B. Reeves, "p38 MAP kinase inhibition ameliorates cisplatin nephrotoxicity in mice," American Journal of Physiology, vol. 289, no. 1, pp. F166-F174, 2005.

[130] H. D. C. Francescato, R. S. Costa, C. G. A. da Silva, and T. M. Coimbra, "Treatment with a p38 MAPK inhibitor attenuates cisplatin nephrotoxicity starting after the beginning of renal damage," Life Sciences, vol. 84, no. 17-18, pp. 590-597, 2009.

[131] J. Luo, T. Tsuji, H. Yasuda, Y. Sun, Y. Fujigaki, and A. Hishida, "The molecular mechanisms of the attenuation of cisplatin-induced acute renal failure by $\mathrm{N}$-acetylcysteine in rats," Nephrology Dialysis Transplantation, vol. 23, no. 7, pp. 2198-2205, 2008.

[132] H. D. C. Francescato, R. S. Costa, F. B. Júnior, and T. M. Coimbra, "Effect of JNK inhibition on cisplatin-induced renal damage," Nephrology Dialysis Transplantation, vol. 22, no. 8, pp. 2138-2148, 2007.

[133] N. Pabla, G. Dong, M. Jiang et al., "Inhibition of PKC $\delta$ reduces cisplatin-induced nephrotoxicity without blocking chemotherapeutic efficacy in mouse models of cancer," Journal of Clinical Investigation, vol. 121, no. 7, pp. 27092722, 2011.

[134] M. A. Perazella and K. Tray, "Selective cyclooxygenase-2 inhibitors: a pattern of nephrotoxicity similar to traditional nonsteroidal anti-inflammatory drugs," American Journal of Medicine, vol. 111, no. 1, pp. 64-67, 2001.

[135] P. Ejaz, K. Bhojani, and V. R. Joshi, "NSAIDs and kidney," Journal of Association of Physicians of India, vol. 52, pp. 632640, 2004.

[136] R. W. Schrier and W. L. Henrich, "Nonsteroidal anti-inflammatory drugs. Caution still indicated," Journal of the American Medical Association, vol. 251, no. 10, pp. 13011302, 1984

[137] C. C. Hou, S. L. Hung, S. H. Kao, T. H. Chen, and H. M. Lee, "Celecoxib induces heme-oxygenase expression in glomerular mesangial cells," Annals of the New York Academy of Sciences, vol. 1042, pp. 235-245, 2005.

[138] N. Pannu and M. K. Nadim, "An overview of drug-induced acute kidney injury," Critical Care Medicine, vol. 36, no. 4, supplement, pp. S216-S223, 2008.

[139] C. A. Naughton, "Drug-induced nephrotoxicity," American Family Physician, vol. 78, no. 6, pp. 743-750, 2008. 

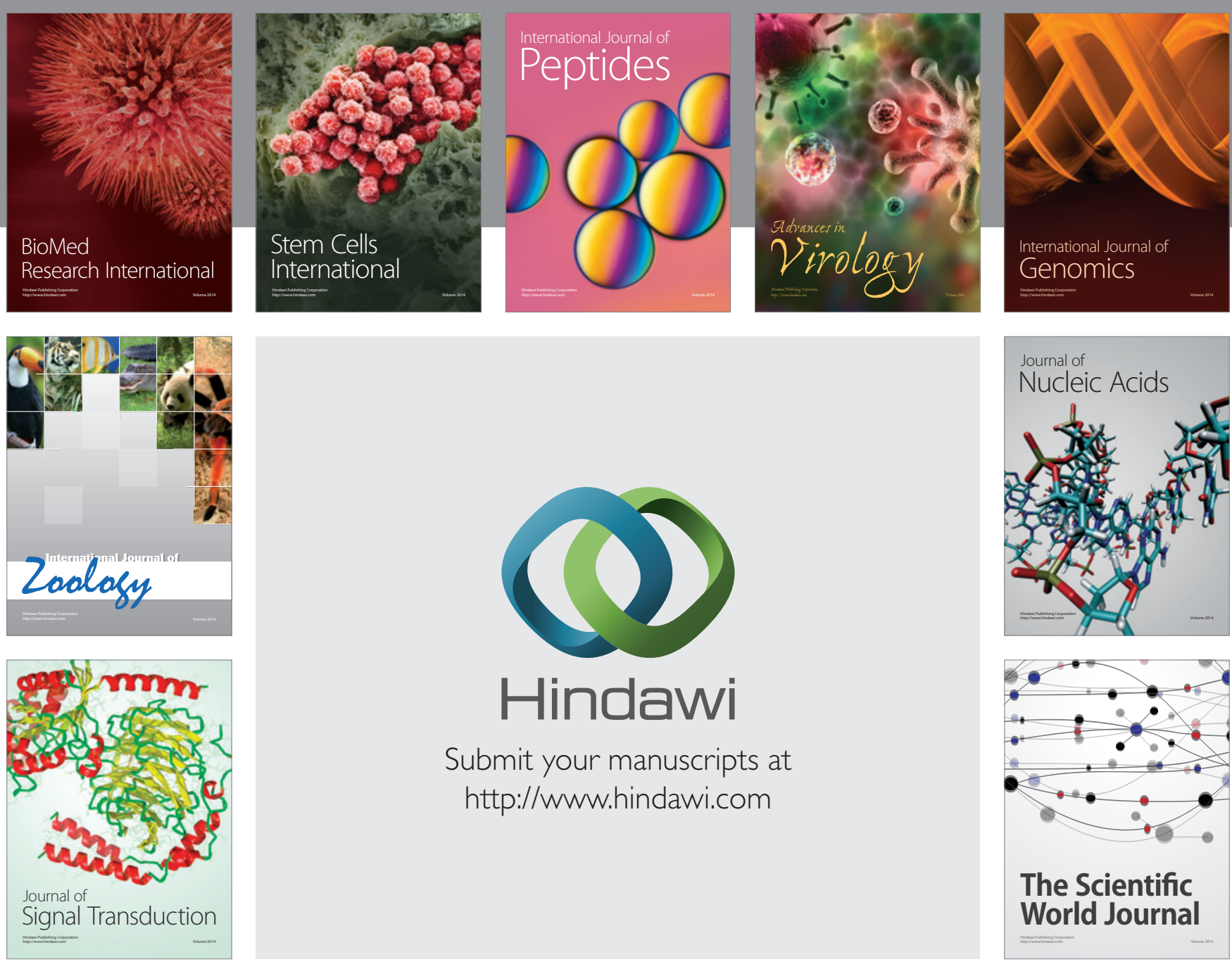

Submit your manuscripts at

http://www.hindawi.com
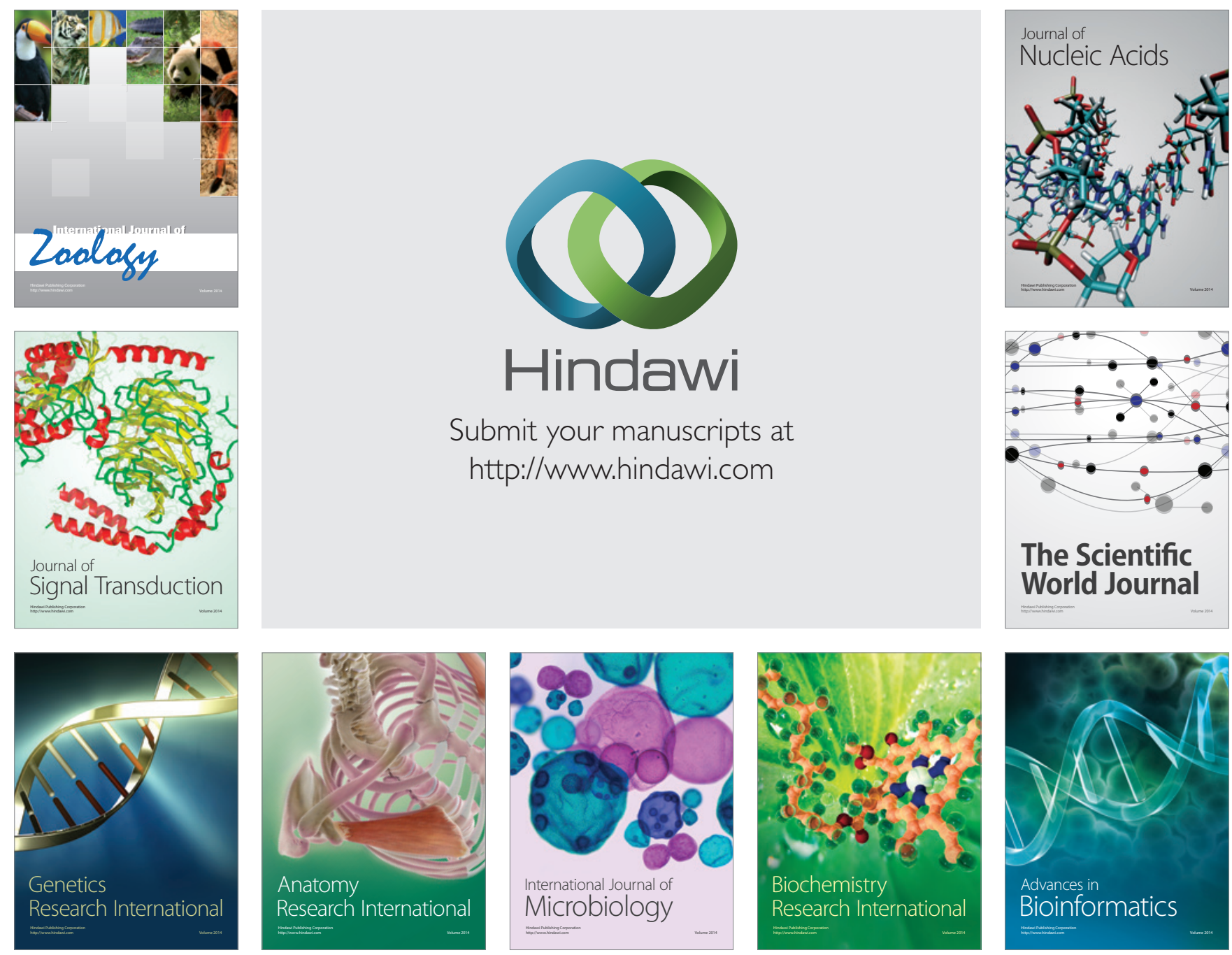

The Scientific World Journal
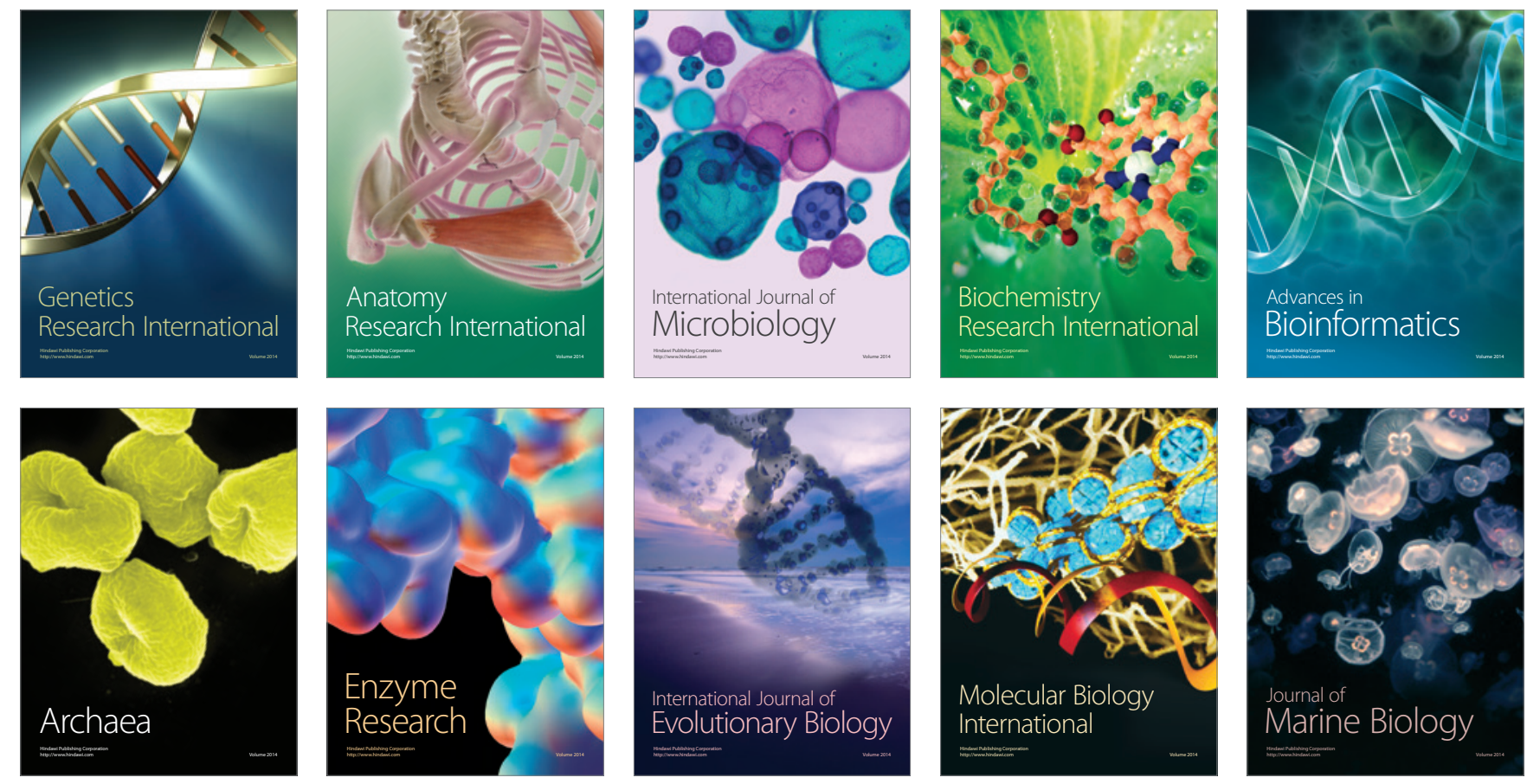